\title{
Migração e diversidade lingüistica em Luanda
}

\author{
Luena Nascimento Nunes Pereira*
}

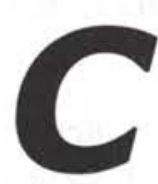

onsiderando a dinâmica migratória em Angola, nas diferentes fases da sua história, pretendo neste artigo traçar alguns aspectos da diversidade lingüística na sua capital, Luanda, levando em conta a especificidade da formação do Estado Nacional neste país da África Central.

Tratar dos deslocamentos populacionais em países africanos remete à formação deste extenso continente povoado através de sucessivas levas migratórias ao longo dos séculos. Migrações que acarretaram em dominação de povos sobre outros, como também em alianças, surgimento de novos povos, formações políticas e sociais de diversos tipos, relações comerciais, expansões religiosas. Assim como em todo o mundo, as migrações são elemento primordial da formação do continente africano e da história de seus diversos povos.

Todavia, a história destas migrações conheceu na África momentos dramáticos como no período do tráfico de escravos, cujo impacto da saída de milhões de pessoas forçosamente deslocadas para as Américas (e também para o Oriente Médio, através do tráfico árabe pelo Oceano Índico), durante mais de três séculos, é difícil de ser estimado.

Por sua vez, o período de ocupação colonial na África, iniciado em fins do século XIX, foi marcado por políticas de fixação e deslocamento de populações obedecendo aos interesses econômicos e estratégicos do poder colonial. Nesse processo, populações foram fixadas, deslocadas e agrupadas, rompendo e transformando toda uma lógica interna de assentamento, de residência, de deslocações para fins comerciais, religiosos e outros. A organização nativa, com a conseqüente distribuição de terras e pessoas de acordo com o desenvolvimento endógeno, através das relações de parentesco, foi alterada de forma mais ou menos radical dependendo da região, do tipo de colonização empregado, do sistema econômico adotado.

Depois, com a ascendência das colônias à independência, a dinâmica das populações sobre o território conheceu uma nova fase. Foi o momento da criação dos Estados Africanos, que assumiram o modelo do Estado-Nação moderno impondo-se sobre realidades muito diversas. Um processo que na Europa levou séculos para ser consolidado (e que na América já dura pouco mais de 150 anos), na África implantou-se em escassas décadas.

A formação do Estado Nacional, que implica, entre outras coisas, na fixação de uma população específica sobre um território delimitado, conheceu na África uma realidade adicionalmente complexa pois, na impossibilidade de retomar as formações políticas anteriores à colonização, estes novos Estados assumiram as fronteiras legadas pelo período colonial, com todas as contradições ali geradas.

Esse processo pode ser verificado no caso de Angola. Tendo contribuído com cerca de $70 \%$ da mão-de-obra escrava para o Brasil, a região do Congo-Angola foi das regiões que mais sofreu com o esvaziamento populacional entre os séculos XVI e XIX devido ao tráfico negreiro. A ocupação efetiva dos portugueses, mais significativa a partir do século XIX, redundou, após extensas guerras de ocupação colonial (nas quais a resistência nativa foi minada com muita violência) na fixação das populações orientada para a produção que beneficiava exclusivamente o poder colonial, tal como em outras regiões da África naquele mesmo período.

A fixação das populações teve efeitos variáveis. Mais facilitada em populações de economia tradicional agrária, foi mais difícil sobre povos pastoris, nômades. Em grupos mais dedicados ao comércio, por exemplo, o controle do poder colonial português sobre suas atividades provocou o desmantelamento da organização social e econômica destas populações.

A expansão das plantações de café e algodão, em meados do século $\mathrm{XX}$, na região norte de Angola, ocasionou a tomada de terras aos africanos pelos colonos e o deslocamento de trabalhadores da região centro do país, mais populoso, para estas plantações, sob o regime de trabalho forçado.

A pressão sobre as terras e o trabalho forçado redundou na fuga dos africanos do norte de Angola para a então colônia do Congo Belga (anos 1940 e 50). Nesse caso, 
atentamos para a coincidência de populações de mesma origem etnolingüística (população Bakongo), dividida pelas fronteiras coloniais portuguesa (Angola), francesa (Congo Brazaville) e belga (Congo Belga). Esta origem comum ${ }^{1}$ facilitou a vida dos emigrantes na colônia belga. A possibilidade de fuga pela fronteira, todavia, não era possível aos trabalhadores vindos da região central, que não dominavam a língua do Norte e tampouco conheciam o território.

Com o começo da guerra anti-colonial (1961), a repressão sobre as populações foi evidente, sobretudo no norte de Angola, onde os conflitos foram iniciados. Em consequência, a emigração para o já independente $\mathrm{Congo}^{2}$ foi muito intensa. Em todo o território afetado pelas ações de guerrilha, a reação portuguesa foi a de deslocar aldeias inteiras e realocá-las em aldeamentos controlados pelo poder colonial, a fim de evitar a adesão popular às guerrilhas independentistas.

Após 14 anos de guerra, Angola conquistou sua independência, em novembro de 1975. Abre-se assim uma nova etapa na dinâmica migratória do país. A atração das populações para as cidades foi um processo marcante nos primeiros anos de independência. Esse fenômeno, comum em outros países, tem a ver com uma maior liberdade das populações que não mais obedecem ao cerceamento imposto pelo antigo regime colonial. Também a necessidade de maior oferta de serviços (de educação, saúde) e de emprego, já marcante no período préindependência, agrava-se com a constituição de um Estado muito fragilizado nos primeiros anos.

$\mathrm{O}$ começo da guerra civil foi outro fator de pressão sobre as populações, que se encaminharam para os centros urbanos, sobretudo a capital, Luanda. Neste mesmo período, verificava-se o retorno dos refugiados dos países vizinhos para Angola, em especial aqueles que se encontravam no Zaire.

A concentração cada vez maior de população na capital, fez com que esta se elevasse de, aproximadamente, $500 \mathrm{mil}$ habitantes em 1975, para quase um milhão de pessoas em 1983 e, 1,6 milhões em 1990. Após um curto período de paz, no qual foram realizadas as primeiras eleições no país (1992), a guerra foi retomada com grande violência e ataque direto aos centros urbanos (com exceção da capital) provocando grande mortandade de civis. Em 2001 a população de Luanda era estimada em quase quatro milhões de pessoas, ou mais de $30 \%$ da população angolana.

Os deslocamentos internos, portanto, passam a ser muito mais expressivos que as migrações internacionais, considerando também que a instabilidade interna e a frágil economia dos países vizinhos, sobretudo o Zaire, dificultou a absorção de população estrangeira.

\section{MIGRAÇÃO NO CONTEXTO DO ESTADO NACIONAL}

A formação dos modernos estados africanos trouxe um novo sentido à questão migratória, em comparação aos deslocamentos pré-coloniais e coloniais. No período pré-colonial, os deslocamentos não obedeciam a fronteiras rígidas, e sim a estratégias de expansão, comerciais, familiares e outras. A passagem de um território a outro geralmente era mediada pelo pagamento de um tributo, não havendo grandes atribulações. Sob a colonização esse processo é determinado pela lógica da produção em benefício do sistema de dominação, cujo centro encontra-se fora do continente. Porém, obedecendo à mesma lógica, os deslocamentos podiam ser facilitados, ou burlados, dependendo da eficácia do sistema repressivo.

$\mathrm{Na}$ atual fase do Estado Moderno, pode-se argumentar que o sistema repressivo nem sempre é eficaz, ocasionando em diversos lugares a fronteira aberta, onde essa passagem é extremamente facilitada (o caso da fronteira norte de Angola). Contudo, o significado da migração é alterado. O estatuto de estrangeiro, de imigrante, ganha um outro peso que implica não somente a sua inserção num sistema econômico e jurídico no país receptor, mas também num sistema identitário e simbólico. A recente lealdade à nação é concebida como algo que deve superar lealdades anteriores étnicas, de parentesco, de identidade lingüística.

O processo em questão trata, portanto, de um certo tipo de homogeneização em busca da consolidação da identidade nacional, garantia necessária ao sucesso do próprio Estado-Nação. A forma de gestão das diversidades internas à nação pode assumir múltiplas formas, mas sempre primará num tipo de corte operado entre "nós e outros", num continuum de exclusão/inclusão adotando-se um viés institucional, político ou cultural.

Assim, o lugar do estrangeiro adquire um significado evidente de alteridade. Contudo, quando consideramos o caso de grupos étnicos cortados por fronteiras nacionais, o processo de identificação torna-se mais problemático, pois, neste caso, percebemos claramente um "embaralhamento" de identidades, a étnica, a nacional e as duas mutuamente transformadas. Este é o caso dos emigrantes refugiados no Zaire que após a independência retornaram a Angola. Este grupo, embora sendo originário do território que deu origem ao Estado Nacional angolano, carrega consigo uma extensa vivência num país vizinho, em muito facilitada pela existência de uma identidade étnica.

\section{ANGOLA E A LÍNGUA PORTUGUESA}

Um dos fatores marcantes da formação do Estado Nacional é a identificação lingüística que possibilita o reconhecimento da nação como integrada. Embora ressalve-se que nem todos os países contam com a identidade lingüística para assegurarem no plano simbólico sua unidade como nação, pode-se dizer que em Angola esse processo foi fundamental. E torna-se também um caso exemplar para a compreensão de um fenômeno que combinou continuidade e ruptura com relação ao seu passado colonial.

A adoção da língua do antigo colonizador como língua oficial foi um processo comum à grande maioria dos 
países africanos. Entre as principais razões para tal, temos o fato das independências nestes países terem sido levadas a cabo por elites modernas, ou seja, educadas à ocidental; a herança de uma estrutura administrativa do período colonial organizada na língua européia e a tentativa de evitar a hegemonia de um grupo étnico sobre outros em torno da disputa sobre uma língua.

Embora comum, este processo não foi realizado sem questionamentos de ordem política e cultural, sobretudo na relação entre a língua oficial e as línguas maternas faladas pela maioria da população; as clivagens de status e poder decorrentes do domínio da língua européia por uma certa camada; e os espaços públicos e privados assumidos pelas línguas oficial e locais.

No caso angolano, deu-se o fato incomum de uma intensa disseminação do português entre a população angolana. Embora sem contar com estatísticas, é assente a expansão do português a ponto de haver uma expressiva parcela da população angolana que tem como sua única língua aquela herdada do colonizador.

São vários os motivos que explicam esse fenômeno. O principal foi a implantação, pelo regime colonial português, de uma política assimilacionista considerada a base ideológica do seu domínio na África. Essa política fundamentava-se na classificação jurídica dos nativos entre indígenas e assimilados, onde aos segundos era garantida uma série de privilégios, entre os quais a liberação do trabalho forçado. Para obter esse estatuto, o nativo deveria adotar hábitos e valores portugueses, considerados "civilizados", entre os quais o domínio da língua portuguesa.

Para além da real extensão do estatuto de assimilado, está embutida na política assimilacionista um profundo desprezo e desvalorização das culturas nativas, rechaçando as estruturas sociais e políticas locais em prol de um modelo "portugalizador", associado à "civilização" e à cristianização das populações submetidas.

A par da imposição cultural ocorre um outro processo, o da incorporação da língua portuguesa por setores urbanos da população. Longe de ser um processo apenas impositivo, verifica-se a positividade da adoção da língua como língua de comunicação comum, inclusive de veiculação de idéias de emancipação naquele que viria a ser o território nacional e que no período colonial ia ganhando consistência como tal no imaginário de setores da sociedade angolana. Durante todo o século $\mathrm{XX}$, a língua portuguesa facilitou a comunicação entre pessoas de diferentes origens. $\mathrm{O}$ período da guerra anti-colonial foi o momento fundamental da expansão da consciência nacionalista, quando guerrilheiros percorriam o território arregimentando pessoas e unificando-as pela esperança de um país livre da opressão colonial. De instrumento de dominação e clivagem entre colonizador e colonizado, o português adquire um caráter unificador entre povos de diferentes línguas e culturas, mas participantes de uma mesma história.

Com a independência, o alastramento da guerra civil, nas décadas subseqüentes, teve também o mesmo efeito de expandir a língua portuguesa, através do exército, por exemplo. Contudo, isso se deu num contexto de implantação do Estado Nacional, havendo também outras variáveis, como a expansão do sistema administrativo, do sistema escolar, da comunicação social, etc.

Embora o governo angolano (exercido por um dos movimentos de libertação, o MPLA - Movimento Popular para a Libertação de Angola $^{3}$ ) declarasse assumir a tarefa de valorizar as culturas - e as línguas - nacionais, na prática, diversos foram os entraves para esta promoção. Uma delas, certamente foi a de valorizar aspectos de unificação do país em detrimento daquilo que distingue os grupos, ou seja, a precedência dos símbolos nacionais sobre os regionais e étnicos.

Outro fator foi a escassa pesquisa produzida antes e depois da Independência sobre as culturas formadoras da nação, estudos lingüísticos, etnológicos e outros, também dificultados pela continuidade da guerra civil. A pouca produção de material didático e literário nas diversas línguas nacionais também dificulta o que se chama de "promoção das línguas nacionais" e a formalização do seu ensino.

A dúvida sobre instaurar um sistema de alfabetização nas línguas maternas e promover uma defasagem entre crianças do meio rural (alfabetizadas na língua materna) e do meio urbano (alfabetizadas na língua oficial) fez recuar o projeto do ensino em línguas maternas em diversos países africanos e não somente em Angola ${ }^{4}$.

Em Angola são consideradas duas categorias de línguas: a língua oficial, portuguesa, e as línguas nacionais ${ }^{5}$. Destas, algumas são veiculadas num noticiário específico da Televisão Pública de Angola (TPA), feito apenas em línguas nacionais. Há uma das cinco emissoras da Rádio Nacional de Angola que emite exclusivamente em línguas nacionais. As emissoras provinciais também produzem programas nas suas línguas locais.

\section{LUANDA: URBANIZAÇÃO E DIVERSIDADE LINGUISTTICA}

A perda de espaço das línguas maternas em Angola deve-se sobretudo ao fenômeno da migração para as cidades, que exige o aprendizado e o uso contínuo do português. A perda do contato com a língua materna implica, numa certa medida, numa perda de conhecimentos referentes ao sistema cultural que a língua remete. Esse sistema cultural está relacionado ao modo de vida rural, que vai sendo deixado para trás.

Os modos de vida, cujos saberes são veiculados pelas línguas específicas, estão ancorados numa tradição que se transmite oralmente. A tradição oral se vê, como em outras partes do planeta, no impasse da perda de espaço pela acelerada urbanização (sem considerar a própria destruição das economias e das vidas provocadas pela guerra), com a deslegitimação do saber tradicional frente aos processos de modernização, veiculados pela escrita.

Perda? Ameaça? Desaparecimento? Não de todo, posto que os modos de existência são, por sua vez, reproduzidos e recriados no espaço urbano, sobretudo 
nas periferias e bairros pobres, destino da maior parte da população migrada para as cidades. E é nestes bairros onde percebemos a diversidade lingüística como um dado interessante para repensar o formato do Estado Nacional, sempre entre a sua necessidade de afirmação unitária e a diversidade de múltiplas faces que abriga.

Retornando ao cenário de Luanda, encontramos hoje um "cadinho" no qual entram em contato diversos grupos de origens e trajetórias ora comuns, ora diferenciadas. Os legados destes diferentes grupos ocasionam a fusão e a recriação de novas identidades que tornam mais complexo o quadro nacional, onde não é possível simplesmente pensar numa mera oposição entre identidade nacional e identidades étnicas, consideradas como culturas homogêneas e auto-referentes.

Fundada no período do tráfico de escravos e com mais de 400 anos de presença portuguesa, Luanda tem no português muito mais que uma língua de dominação ou mesmo língua oficial ou administrativa: Luanda é uma cidade onde a chamada "lusofonia" ganha um sentido profundo.

Essa lusofonia não tem, no entanto, qualquer significado de pureza ou "casticidade". O português falado na Luanda de ontem e hoje foi bastante transformado pelas línguas locais, notadamente o kimbundo, língua materna dos habitantes da região da capital. Tal como o português enraizado dos brasileiros, o português de Luanda também vem cheio de modos, sotaques, vocábulos e formas de construção da língua que dizem, por vezes, mais respeito às estruturas lingüísticas africanas que propriamente ao português falado em Portugal.

Apesar disto, a desvalorização empreendida pelo poder colonial sobre as línguas nativas provocou um sentimento de auto-desvalorização dessas línguas, que até hoje se faz sentir em certas camadas da população, em especial as de urbanização mais antiga. Elas carregam uma visão da língua materna como inferior, que não vale a pena ser falada ou aprendida. Mesmo com a veiculação de um ideário de valorização das culturas, com a positividade atribuída às línguas como um fator de identidade e afirmação cultural, o sentimento de "inutilidade" das línguas locais em prol das "ocidentais" persiste, disfarçado de "pragmatismo". Ainda que os bilingües sejam invejados e admirados, pouco se faz para recuperar o uso das línguas maternas nas cidades ${ }^{6}$.

A ignorância ou resistência às línguas de origem por parte de camadas da população "luandense", convive com o "multilingüismo" das populações vindas mais recentemente de outras partes do país. Essas línguas, contudo, ficam de certa forma restritas ao espaço privado, doméstico, sendo acionadas nos momentos em que se deseja demarcar uma certa diferenciação, como nos momentos de tensão, conflitos ou de festejos e comemorações. Outro lugar interessante de afirmação da diversidade lingüística é o espaço religioso. Os cultos e missas, sobretudo nos bairros da periferia, são muitas vezes realizados em várias línguas, sobretudo os cânticos, dependendo da composição da audiência.

O caso mais interessante para percebermos a dinâmica lingüística na capital advém da chegada dos regressados vindos do Zaire à capital angolana após a independência do país. O retorno deste contingente ${ }^{7}$, vindos em levas sobretudo durante a segunda metade da década de 1970 e década de 80 (antes portanto, da chegada maciça de deslocados de todo o país por ocasião da guerra mais violenta, que se deu após 1992) trouxe consigo os hábitos e costumes apreendidos durante uma longa vivência no Zaire. Entre eles, uma língua estranha aos angolanos, o lingala, veicular da região da capital zairense, Kinshasa.

A experiência urbana destes cidadãos não facilitava sua identificação frente aos locais como emigrantes rurais. A inserção de muitos indivíduos formados no Zaire nos quadros da administração do Estado e a montagem do comércio paralelo num país de orientação socialista foram elementos que caracterizaram este contingente como um grupo entre si bastante diferenciado e dinâmico. Os que possuíam formação secundária e superior eram mais hábeis no francês, tendo que se adaptar rapidamente ao uso da língua portuguesa para exercerem suas profissões. Já os setores que ganharam a vida no comércio ilegal não tinham tanta pressa no aprendizado do português. Mais: muitos deles resistiam ao aprendizado de uma língua que remetia ao antigo colonizador e não compreendiam por que a maior parte das pessoas só sabia expressar-se na língua oficial, não dominando suas línguas de origem.

O lingala passou assim a concorrer com o português em certos espaços como nos principais mercados livres, que à margem do poder público iam se expandindo. Língua também ouvida no transporte clandestino dos candongueiros (as lotações), ganhando assim um lugar que, se não publicamente reconhecido, não se restringia ao espaço doméstico e privado das periferias.

Para além de considerações de ordem política que identificavam os originários do norte do país que viveram no Zaire com a FNLA, partido inimigo do MPLA desde os tempos da guerrilha anti-colonial, a presença dos "regressados", de seus hábitos diferenciados, sua rápida inserção e visibilidade nas atividades econômicas da cidade, sobretudo a língua lingala, veiculada insistentemente nas ruas, mercados e meios de transporte, ocasionaram o estigma de estrangeiros aos portadores de uma língua não nacional.

O português passou assim a ser considerado um demarcador de nacionalidade, de identidade nacional. Ainda que tenha sido visto como língua de unidade nacional, a língua da literatura e do Estado, jamais fora considerada uma língua nacional exclusiva, no sentido de que pudesse definir quem era ou não angolano a partir da competência do seu uso. Em Luanda, a partir da entrada dos regressados, que tinham como língua principal não o kikongo, língua materna Bakongo, mas o lingala, língua veicular de Kinshasa, o português passou a ser usado pelos luandenses como um demarcador de nacionalidade e de "angolanidade": "não são angolanos, pois nem falam o português".

Reagindo ao estereótipo de estrangeiros, os bakongo regressados, por sua vez, estranhavam certos 
comportamentos dos "luandenses", principalmente a importância atribuída à língua portuguesa, considerada uma língua nacional. O centro das distinções para os regressados estava na reivindicação de uma "africanidade" contraposta a uma excessiva "ocidentalização" dos habitantes de Luanda, mais percebida como "portugalização". O uso quase exclusivo do português em Luanda, a não competência da maioria dos seus habitantes em qualquer língua africana, o modo de vestir e outros comportamentos, foram sendo também tachados de aportuguesados e, por vezes, de "abrasileirados". A "africanidade Bakongo/regressada" seria exercida num modo de ser e de estar, evidenciado entre outras características pela competência nas línguas africanas. O lingala, quando definido como uma "língua africana", esconde o fato de não ser uma língua angolana. Assim, há também o apelo a uma "identidade bantu" referindo-se a todo complexo cultural da região central e austral da África, que se estende dos Camarões à África do Sul, e que partilha o mesmo tronco lingüístico.

Assim, percebe-se em distintos grupos a criação de critérios divergentes para a definição de nacionalidade, de legitimação de identidades, refletindo visões de mundo produzidas por culturas e contextos históricos diferenciados, que são atualizadas e postas em confronto no processo de construção da nação.

\section{A DIVERSIDADE LINGUISTICA NUM GRUPO ÉTNICO: OS BAKONGO}

Internamente ao grupo Bakongo podemos perceber a coexistência de várias línguas. O kikongo, língua materna, divide espaço com a língua portuguesa, com o lingala e, por vezes, com o francês.

Assim, se para a maior parte dos grupos em Angola a convivência lingüística se dá geralmente entre uma língua materna e o português, os Bakongo que regressaram do Congo (e parte dos Bakongo que receberam a influência deste contingente) operam três, por vezes quatro línguas. Os lugares e situações em que estas línguas são acionadas variam de acordo com o contexto e com o interlocutor, onde entram também as variáveis de geração e gênero.

A língua portuguesa, ao longo dos anos em que os chamados "regressados" vivem na capital do país, impõe-se ao aprendizado de todos como uma necessidade inescapável para o convívio com a "sociedade nacional". O "estigma" atribuído aos que retornaram do Zaire foi em parte se diluindo na medida em que a habilidade com o manejo da língua oficial crescia. O inconfundível sotaque "zairense" dos adultos é imperceptível nas crianças e jovens que freqüentam a escola ao lado de crianças de outras origens, formando uma geração que carrega consigo tanto valores, costumes e visões de mundo dos seus pais, como os que aprende na cidade de Luanda no convívio com outros grupos.

A língua portuguesa é, portanto, a língua que se usa no trabalho, nas ruas, escolas, serviços públicos, aquela que se ouve majoritariamente nos meios de comunicação, em todos os lugares que se convenciona chamar de "espaço público".

No espaço doméstico, entre os Bakongo, o português também se faz presente, mas ao lado do lingala, sobretudo naqueles bairros em que os Bakongo são a maioria dos moradores. O lingala também é muito ouvido nos mercados (chamadas "praças") em que a presença dos comerciantes bakongo é expressiva. O lingala tornou-se uma língua tão comum nos mercados que vemos pessoas que nunca estiveram no Congo manejá-la sem problemas.

O lingala é a língua preferida dos adultos que estiveram no Congo e dos jovens que consomem em larga escala a contagiante música congolesa. Embora as crianças aprendam o lingala bem cedo, têm preferência pelo uso do português, aprendido na escola, e em casa, estimuladas pelos pais, que não desejam que seus filhos sintam a mesma discriminação que sofreram por falarem mal o português.

Já o francês é utilizado pelas pessoas que estudaram no Zaire e nela têm uma língua de prestígio, que traz facilidades para um grupo que faz da mobilidade uma forma de vida. É uma língua muito restrita às pessoas formadas, aos intelectuais, estando relegada a um pequeno círculo, em situações pontuais.

O kikongo é a língua mais utilizada pelos mais velhos, em situação doméstica ou ritual. Pessoas recém-chegadas da área bakongo também expressam-se mais na língua materna. As mulheres mais velhas também têm preferência por esta língua, até porque por vezes tiveram dificuldade em aprender tanto o lingala no Congo como o português em Angola.

É nas cerimônias e nos rituais que o kikongo ganha expressão máxima. Reuniões familiares convocadas para a resolução de problemas, celebração de casamentos tradicionais e as longas cerimônias de óbitos são o momento em que o kikongo emerge como a língua na qual é transmitida toda a sabedoria tradicional tornando possível o encaminhamento e a resolução das situações deste grupo social que são expressas ritualmente.

Através dos provérbios e fórmulas, dos discursos e narrativas que os "mais velhos"8 desfiam perante a uma audiência participativa, o kikongo se afirma como símbolo da unidade do grupo e como reiteração de uma cultura e de saberes que, recriando-se no espaço urbano, são perpetuados.

A continuidade dos costumes do casamento tradicional, do óbito, da resolução de problemas que exigem a presença e participação das famílias envolvidas, tanto mantém viva a língua, como esta, por sua vez, confere sentido às transformações necessariamente engendradas nestes rituais.

\section{CONCLUSÃO}

$\mathrm{O}$ estatuto dàs línguas nacionais em Angola e o seu justo tratamento pelo Estado e pela sociedade são temas que têm estado em pauta no debate nacional, seja nas rádios e por vezes na televisão. Há, por exemplo, projetos para introdução das línguas maternas nas escolas, ou projetos de resgate da tradição oral com recolha de 
depoimentos e narrativas dos mais velhos. Sobressai, tanto entre os intelectuais como entre a população comum (que intervém nos programas de rádio), a perspectiva pessimista que as línguas cedo ou tarde serão esquecidas e desaparecerão frente ao rolo compressor da língua portuguesa. Com elas, segundo essa visão, desapareceriam os conhecimentos tradicionais e as culturas por elas sustentadas.

$\mathrm{Na}$ verdade, muito das opiniões sobre o assunto tem a marca de observações muito restritas à capital do país. A escassez de estudos sobre a atual situação das línguas maternas e de como os diferentes grupos lidam com o seu repertório lingüístico em todo o território não permite avançar em análises mais realistas e refinadas.

É de ressaltar que a guerra, menos que a urbanização, tem sido responsável pela crise que porventura se possa atribuir às línguas nacionais. Os deslocamentos forçados de populações para as cidades, a perda brusca de referências são fatores que explicam a interrupção no desenvolvimento das línguas. A impossibilidade das pessoas residentes nas cidades de participarem com seus familiares de ocasiões importantes nas suas áreas de origem - colheitas, festas, casamentos, óbitos - faz perder o contato e as trocas culturais entre campo e cidade, perdendo as línguas seu necessário dinamismo.

Atualmente esperamos estar assistindo a uma nova etapa na história angolana com o cessar-fogo e o retorno aos acordos de paz obtidos este ano (2002). Com a garantia da paz e do desarmamento, poderá estar breve o estabelecimento da normalidade do trânsito em todo o país. Isto certamente não significará que a maior parte das pessoas que hoje se encontra nas cidades tornará a fixar-se no campo, mas me parece certo afirmar que o retorno periódico às áreas de origem, permitindo a volta do contato entre famílias separadas, a reconstituição das atividades econômicas e sociais que caracterizam a normalização da vida garantirá, por conseguinte, a revivescência cultural e lingüística. A partir daí poderemos conhecer, numa nova dinâmica não mais pautada pela guerra e pela tragédia, um novo desenvolvimento para os diferentes povos da mesma Angola.

* Luena Nascimento Nunes Pereira é doutoranda do Programa de Pós-Graduação em Antropologia Social/USP e Bolsista FAPESP.

\section{NOTAS}

1 - A população bakongo fazia parte do antigo Reino do Congo, formado em fins do século XIII. Este reino encontrou a sua decadência durante o tráfico de escravos e desintegrou-se com a partilha colonial que o dividiu sob o controle das três potências coloniais já mencionadas.

2. O Congo Belga tornou-se a independente República do Congo Democrático em 30/6/ 1960 , mudando seu nome depois para Zaire, em 1971. Em 1998, seu nome volta a ser República do Congo Democrático. Neste artigo faço referência tanto ao Congo como ao Zaire para designar o mesmo país. Não faço referência ao Congo Brazzaville, antigo Congo Francês.

3 - Os outros movimentos de libertação existentes, a FNLA (Frente Nacional de Libertação de Angola) e UNITA (União para a Independência Total de Angola) ficaram fora do governo que assumiu o poder em 1975. A UNITA veio protagonizando a guerra civil contra - MPLA até bem recentemente. A FNLA, enfraquecida, retirou-se da cena política por um longo tempo, retornando com o processo de abertura democrática, no começo dos anos 1990.

4 - Instituto de Línguas Nacionais, criado junto a Secretaria de Estado da Cultura, é dedicado à pesquisa das línguas nacionais e produção de material didático. O Instituto produziu os alfabetos e o pouco material disponível em algumas das principais linguas nacionais angolanas.

5 - A classificação das etnias em Angola leva em conta o critério lingüístico. Dessa forma, o país conta com cerca de dez grupos étnicos, sendo que os três maiores grupos - Ovimbundu (língua umbundo), Ambundo (lingua kimbundo) e Bakongo (língua kikongo) - somam 75\% da sua população. Dentre outros grupos estão os Lunda-Tchokwe, Nganguela, Herero, Ovambo, Nyaneka-Humbe. Estas populaçōes são do tronco bantu, que predomina na região centrosul da África. Outros pequenos grupos nãobantu em Angola são os Khun, vulgarmente denominado de "bosquimanes", presentes no sul do país.

6 - A realidade das línguas maternas nas províncias é bem diferente da capital. $\mathrm{Na}$ área rural as línguas locais são as mais utilizadas, formando uma população bilingüe nos centros urbanos. Não há, contudo, dados empíricos sistematizados para avançar a discussão sobre este ponto.
7 - Não há qualquer estatística sobre o número de pessoas que retornaram a Angola vindos do Congo/Zaire. Todavia, estimo esse número, na cidade de Luanda, em torno de 300 mil pessoas, levando em conta os bairros periféricos cuja população bakongo é majoritária. Há que considerar também que a guerra reiniciada a partir de 1992 acarretou uma intensa migração das províncias do norte do país (população Bakongo) para a capital.

8. Em Angola "mais-velho" năo se refere somente a um idoso (pessoa mais velha), mas é utilizada quase que como um cargo social. Refere-se a alguém de proeminência, um chefe de familia extensa, ou que assume responsabilidades reconhecidas em seu meio social.

\section{REFERÊNCIASBIBLIOGRÁFICAS}

AMADO, Filipe R.; CRUZ, Fausto \& HAKKERT, Ralph

(1992) "Urbanizaçã̃o e desurbanização em Angola". In: Ciências Sociais: Textos de análise III. Luanda, Codesria, 25-49.

ANDERSON, Benedict

(1989) Nação e Consciência Nacional. São Paulo, Editora Ática.

CAHEN, Michel (org.)

(1989) "Cidades e Vilas": Bourges et Villes en Afrique Lusophone. Paris: L'Harmattan.

CONCEIÇĀO NETO, Maria da

(1992) As Fronteiras por Dentro da Nação: Divisōes Étnicas, Sócio-Econômicas e Sócio-Políticas numa Perspectiva Histórica. Angola: A Crise e o Desafio Democrático. Luanda: ADRA: Programa Angola-Canadá. p. $43-60$.

HEIMER, Franz-Wilhelm

(1980) O processo de descolonização em Angola, 1974-1976. Lisboa, A Regra do Jogo.

MABEKO TALI, Jean-Michel

(1999) "Congolenses", "congoleses", "zairenses": le poids des mots et des désignations dans l'immigration centreafricaine en Angola. Colloque: Etre etranger et migrant en Afrique au Xxe siècle. Paris.

PEREIRA, Luena Nascimento Nunes (2000) Os regressados na cidade de Luanda: um estudo sobre identidade étnica e nacional em Angola. Dissertação de Mestrado em Antropologia Social, FFLCH/ USP.

SERRANO, Carlos Moreira $\mathrm{H}$. (1988) Angola: nasce uma nação. Tese de doutoramento em Antropologia Social, FFLCH/USP.

SERRANO, Carlos Moreira $\mathrm{H}$. (1992) "O processo de constituiçāo dos estados nacionais e as questōes culturais". Seminário sobre paises africanos de língua portuguesa. São Paulo, FUNDAP, p. 85102. 